\title{
Performance of a flat panel reactor in the continuous culture of microalgae in urban wastewater: Prediction from a batch experiment
}

\author{
J. Ruiz ${ }^{\text {a,* }}$, P.D. Álvarez-Díaz a , Z. Arbib ${ }^{\text {a }}$, C. Garrido-Pérez a , J. Barragán ${ }^{\text {a,b }}$, J.A. Perales ${ }^{\text {a }}$

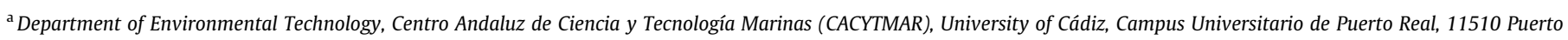 \\ Real, Cádiz, Spain \\ ${ }^{\mathrm{b}}$ Chiclana Natural S.A. Pza. de España S.N. 11130 Chiclana de la Frontera, Cádiz, Spain
}

\section{H I G H L I G H T S}

- We grow Scenedesmus obliquus in urban wastewater in batch and continuous operation.

- Biomass in continuous operation can be predicted based on batch growth kinetics.

- Optimum operation residence times are based on specific growth rate from batch.

- Optimum hydraulic retention time depends on the objective of the culture.

\section{A R T I C L E I N F O}

\section{Article history:}

Received 23 July 2012

Received in revised form 23 September

2012

Accepted 26 September 2012

Available online 5 October 2012

\section{Keywords:}

Scenedesmus obliquus

Urban wastewater

Nutrient removal

Continuous culture

\begin{abstract}
A B S T R A C T
A laboratory-scale flat panel photobioreactor was operated for the continuous growth of Scenedesmus obliquus and consequent removal of nutrients in wastewater. This study develops a simple model by which biomass values in continuous operation can be predicted from kinetic growth parameters obtained from a shorter batch experiment. Based on this study, biomass concentrations and productivities in continuous operation can be successfully predicted as a function of the specific hydraulic retention time (HRT) assumed. Considerable biomass production and nutrient uptake from wastewater were achieved in the experiment. Optimum operating conditions for the reactor depend on the particular objective: the maximization of biomass production and carbon dioxide biofixation involves a $H R T$ of $2 \mu^{-1}$ (specific growth rate), whereas efficient nutrient removal involves a HRT as close as possible to $\mu^{-1}$ (as long as discharges comply fully with the parameters set); alternatively biomass intended for biodiesel or biogas production would involve a $H R T>2 \mu^{-1}$.
\end{abstract}

(c) 2012 Elsevier Ltd. All rights reserved.

\section{Introduction}

Coastal and enclosed water bodies are becoming increasingly enriched in nutrients; eutrophication represents a very grave threat to the long-term health and functioning of estuarine environments and ecosystems around the world (Kennish and de Jonge, 2012). Urban wastewaters and agricultural runoff are the main sources of anthropogenic nutrients accumulating in these environments. In order to reduce this eutrophication contingency plans need to be focused fundamentally on nutrient abatement from such wastewater discharges. Microalgae technology for the removal of nutrients from wastewater is an interesting potential alternative to conventional biological technologies aimed at reducing nutrients (Ruiz et al., 2011).

\footnotetext{
* Corresponding author. Tel.: +34 956016587; fax: +34 956016746.

E-mail address: jesus.ruizgonzalez@uca.es (J. Ruiz).
}

In the early 20th century, the first wastewater treatment processes came into operation, and despite being a well-known field of technology nowadays, the correct dimensioning of a wastewater treatment plant (WWTP) is still difficult. This task becomes even more complex when designing and installing a non-conventional process such as the culture of microalgae for the removal of nutrients.

For the design and operation of WWTP, models of activated sludge processes are used, e.g., the activated sludge model No. 1 (ASM1) (Henze et al., 1987). These models are based on wastewater composition data, influent load profiles and various other parameters, where lab-scale experiments may be required to obtain the correct values, i.e. the determination of the appropriate activated sludge kinetics. Running suitable lab-scale experiments is helpful for correctly dimensioning such processes.

In the present study, a simple mathematical model has been developed whereby a scenario of continuous growth of the selected microalgae can be predicted from shorter batch experiments. The 


\begin{tabular}{|c|c|c|c|}
\hline \multicolumn{4}{|c|}{ Nomenclature } \\
\hline $\begin{array}{l}H R T \\
m_{\text {in }}\end{array}$ & $\begin{array}{l}\text { hydraulic retention time } \\
\text { biomass input present in the feed stream }\left(\mathrm{M} \mathrm{T}^{-1}\right)\end{array}$ & $X_{\mathrm{m}}$ & $\begin{array}{l}\text { maximum concentration that the system can achieve in } \\
\text { batch }\left(\mathrm{M} \mathrm{L}^{-3}\right)\end{array}$ \\
\hline$m_{\text {out }}$ & biomass output from the reactor $\left(\mathrm{M} \mathrm{T}^{-1}\right)$ & $X_{\text {out }}$ & concentration of biomass as output from the reactor \\
\hline$m_{\text {prod }}$ & biomass produced in the reactor $\left(\mathrm{M} \mathrm{T}^{-1}\right)$ & & $\left(\mathrm{M} \cdot \mathrm{L}^{-3}\right)$ \\
\hline MM & molecular mass $\left(\mathrm{M} \cdot \mathrm{N}^{-1}\right)$ & $X_{\mathrm{o}}$ & initial cell concentration $\left(\mathrm{M} \mathrm{L}^{-3}\right)$ \\
\hline$P$ & volumetric productivity $\left(\mathrm{M} \cdot \mathrm{L}^{-3} \cdot \mathrm{T}^{-1}\right)$ & $X_{10}$ & cell concentration $10 \%$ higher than $X_{\mathrm{o}}\left(\mathrm{M} \cdot \mathrm{L}^{-3}\right)$ \\
\hline $\mathrm{PCO}_{2}$ & carbon dioxide fixation rate $\left(\mathrm{M} \mathrm{L}^{-3} \mathrm{~T}^{-1}\right)$ & $X_{90}$ & biomass value of $90 \%$ of $X_{\mathrm{m}}\left(\mathrm{M} \mathrm{L}^{-3}\right)$ \\
\hline$Q$ & flow rate $\left(\mathrm{L}^{3} \mathrm{~T}^{-1}\right)$ & $\delta m / \delta t$ & change in biomass $\left(\mathrm{M} \cdot \mathrm{T}^{-1}\right)$ \\
\hline$t_{\mathrm{m}}$ & time required to reach $X_{\mathrm{m}}(\mathrm{T})$ & $\delta X(t) / \delta t$ & velocity of change of microorganism concentration \\
\hline$t_{\mathrm{o}}$ & initial time $(\mathrm{T})$ & & $\left(\mathrm{M} \cdot \mathrm{L}^{-3} \cdot \mathrm{T}^{-1}\right)$ \\
\hline$t_{90}$ & time required to reach $X_{90}(\mathrm{~T})$ & $\mu$ & maximum specific growth rate $\left(\mathrm{T}^{-1}\right)$ \\
\hline$t_{10}$ & time required to reach $X_{10}(\mathrm{~T})$ & $\theta$ & $H R T$ in the reactor $(\mathrm{T})$ \\
\hline$V$ & reactor volume $\left(\mathrm{L}^{3}\right)$ & $\theta_{\mathrm{P}}$ & $H R T$ at maximum productivity $(\mathrm{T})$ \\
\hline
\end{tabular}

experimental lab-scale work needed prior to plant design could be made simpler, and the time and cost involved in operating a chemostat could be avoided or reduced.

The freshwater microalgae Scenedesmus sp. is particularly suitable for culture in secondary effluent wastewater and for the removal of nutrients (Zhang et al., 2008). Various screenings have shown that Scenedesmus sp. has an adequate fatty acid profile for producing biodiesel (Gouveia and Oliveira, 2009) and very high biomass concentration, very high lipid content and great ability to adapt to growth in typical effluent wastewaters (Xin et al., 2010). For these reasons, Scenedesmus obliquus has been selected for this study; it has been cultured in wastewater in two successive stages, first in batch and then continuously. Various HRT have been tested to determine whether the values obtained from the continuous process fit those predicted by the model from the batch experimental values.

\section{Methods}

\subsection{Microorganism}

Freshwater S. obliquus (SAG 276-10) was obtained from Sammlung von Algenkulturen, Pflanzenphysiologisches Institut (Universität Göttingen, Germany). Inocula was incubated in synthetic culture medium Combo twofold (Kilham et al., 1998) and maintained in exponential growth at a temperature of $20 \pm 1{ }^{\circ} \mathrm{C}$, a light intensity of $250 \mu \mathrm{mol} \mathrm{m}{ }^{-2} \mathrm{~s}^{-1}$ and a 14:10 h light:dark cycle.

\subsection{Reactor set-up and experiment}

A flat panel photobioreactor was used for the culture of the selected microorganism; an initial batch experiment was followed by continuous culture. The photobioreactor consisted of four transparent methacrylate sheets joined together. The reactor had a working volume of $4.5 \mathrm{~L}$, a light path of $44 \mathrm{~mm}$ and an illuminated area of $1,022 \mathrm{~cm}^{2}(28.7 \times 35.6 \mathrm{~cm})$. The system was aerated at an airflow of $2.81 \mathrm{~min}^{-1}(0.63 \mathrm{vvm})$, enriched in $\mathrm{CO}_{2}$ (5\%), a proportion similar to the combustion gasses of fossil fuel power plants burning natural gas. Air was bubbled through in the form of micro-bubbles, which kept the reactor medium fully mixed. The temperature was maintained constant at $20 \pm 1{ }^{\circ} \mathrm{C}$. Illumination was provided by eight fluorescent lamps (4 PHILIPS Master TLD $58 \mathrm{~W} /$ 840 Cool White and 4 SYLVANIA Grolux F58 W/GRO-T8 Daylight) placed on one side of the photobioreactor. The incident light inten- sity was of $250 \mu \mathrm{mol} \mathrm{m}^{-2} \mathrm{~s}^{-1}$ with a photoperiod of 14:10 h light:dark cycle. A diagram of the system is shown as Fig. 1.

The culture medium used was secondary effluent from the WWTP located in the town of Arcos de la Frontera (34,300 equivalent inhabitants) in the Province of Cádiz, Spain $\left(36^{\circ} 44^{\prime} 56.56^{\prime \prime} \mathrm{N}\right.$, $5^{\circ} 47^{\prime} 37.12^{\prime \prime} \mathrm{O}$ ). Before sampling, this wastewater had been submitted to preliminary screening, primary settling, activated sludge and secondary settling processes; the secondary effluent did not undergo any further processing after the samples were taken from the WWTP; it was fed directly to the reactor. The wastewaters used in this work were grab samples taken on different days; therefore the composition of the culture medium varied during the experiment. After inoculation, the culture was grown in batch mode until the stationary phase was reached (i.e. a daily increase in biomass of less than 1\%) in order to obtain a high biomass concentration and to determine the batch growth kinetic parameters. The medium was then supplied during the light phase at a constant dilution rate to obtain a pre-determined steady state. Each steady state was defined as a constant biomass concentration for the duration of at least one $H R T$, considering a standard deviation value of less than $10 \%$ as constant. Subsequently, the feed rate was increased in a series of six experiments, each for a different, progressively shorter duration of $H R T$, as follows: 3.4, 2.8, 2.3, 1.7, 1.1 and $0.5 \mathrm{~d}$.

Once steady state was reached, samples for biomass, chemical oxygen demand (COD) and nutrients analysis were taken from the reactor on a daily basis for a period of at least 3 days.

\subsection{Analysis of responses}

\subsubsection{Biomass}

Daily biomass concentration was measured gravimetrically as dry weight according to the standardized 2540-D method (APHA, AWWA, WEF, 1992).

During steady state, biomass was harvested by centrifugation (Centrifuge Mixtasel-BL Selecta ${ }^{\circledR}$ ) at $4200 \mathrm{rpm}$ for $10 \mathrm{~min}$. The resulting pellets were rinsed twice with deionized water for resuspending and centrifuging. Algae pellets were dried in a lyophilizer (Labconco, FreeZone Triad Cascade Benchtop) and ground to powder. This powder was used for all further biomass composition analyses.

Elementary analysis of carbon and nitrogen (percentage) of dry biomass was performed in duplicate using an elementary analyzer (LECO CHNS-932, Leco Corporation).

An acid digestion of the dry biomass was performed in duplicate in a microwave digester (ETHOS 1600, Milestone); and total 


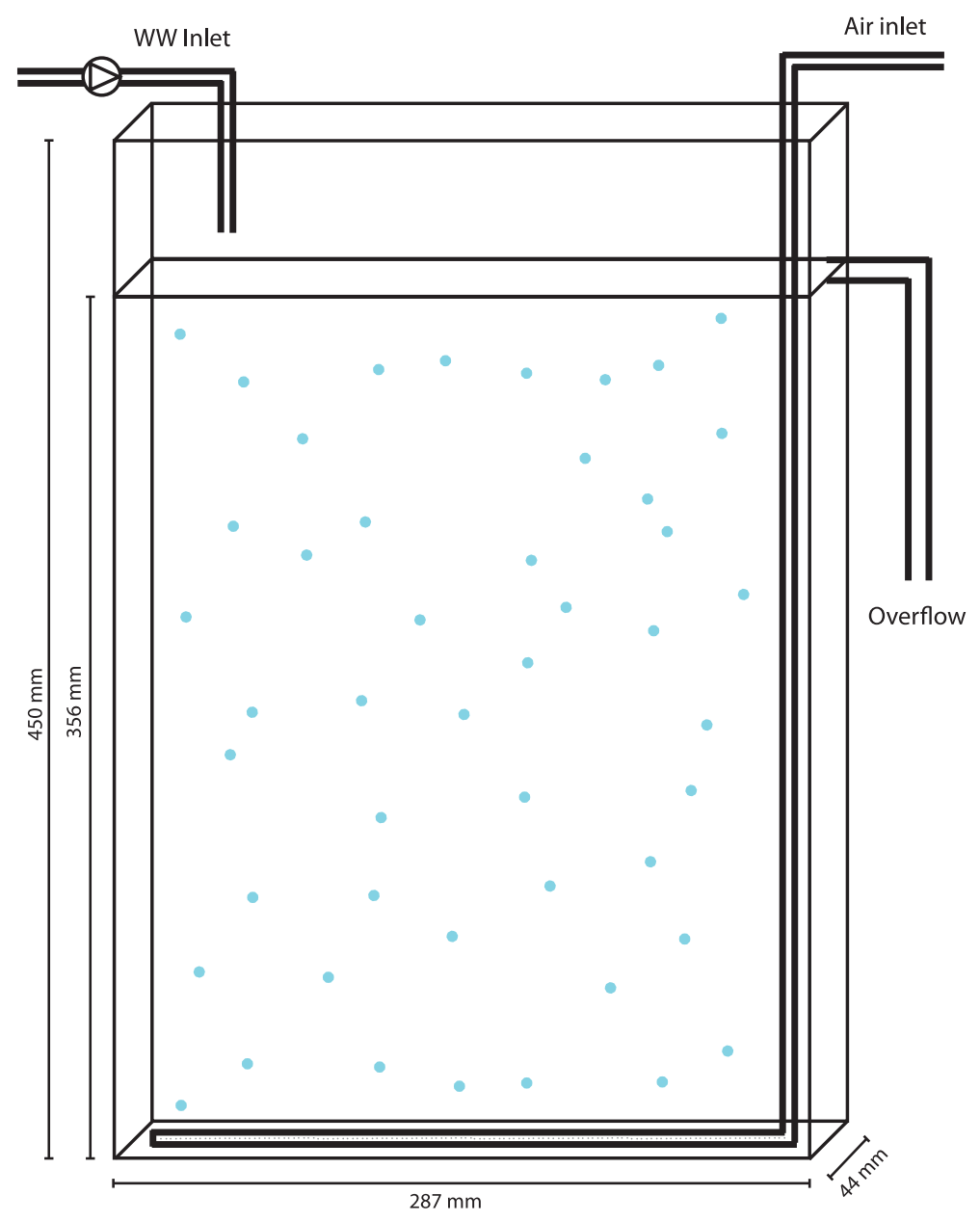

Fig. 1. Diagram of the experimental setup.

phosphorus was determined by means of inductively coupled plasma atomic emission spectroscopy (ICP-AES, Iris intrepid, Thermo Elemental).

Biomass lipids content was also determined in duplicate. Lipids were extracted according to a modified method reported by Takagi et al. (2006) and Wiltshire et al. (2000). To $90 \mathrm{mg}$ of lyophilized pellets, $12 \mathrm{ml}$ of $2: 1$ trichloromethane:methanol mixture and $0.6 \mathrm{~g}$ of analytical grade quartz were added and the mixture was sonicated in a bath $(60 \mathrm{kHz} ; 360 \mathrm{~W})$ for $90 \mathrm{~min}$. Extraction was performed twice and the two extracts obtained were mixed together, centrifuged and filtered to ensure quartz separation. The filtrate was evaporated under reduced pressure in a rotary evaporator. The remainder was dried at $100-105^{\circ} \mathrm{C}$ for $12 \mathrm{~h}$ and weighed as total lipid.

\subsubsection{COD, total nitrogen and total phosphorus determinations}

Samples for nutrient analysis were taken daily from the reactor and then filtered through a fiber filter of $0.45 \mu \mathrm{m}$ pore diameter (PALL Corporation, Type A/E) to separate out the biomass.

Soluble COD was determined according to Standard Methods 5220-D (APHA, AWWA, WEF, 1992). Total nitrogen and total phosphorus were measured colorimetrically as nitrate and phosphate after the sample had been oxidized. The determination was based on the method proposed by (Köthe and Bitsch, 1992), dissolving 1.5 microspoons of Oxisolv ${ }^{\circledR}$ (Merck KGaA, Darmstadt, Germany) in $10 \mathrm{ml}$ of sample, then incubating at $100{ }^{\circ} \mathrm{C}$ for $1 \mathrm{~h}$ to completely oxidize the phosphorus and nitrogen. After being allowed to cool, nitrate determinations were performed using a Spectroquant ${ }^{\circledR}$ test kit (Cod. 1.14773.0001 (Merck)), and phosphates were determined according to the method 4500-P E (APHA, AWWA, WEF, 1992).

\subsection{Data analysis}

Data kinetic modeling was performed using the STATISTICA software (StatSoft, Inc. Version 7.0., 2004). The Quasi-Newton method was used for non-linear regression, with a convergence criterion of $10^{-4}$.

\subsection{Model for biomass growth evolution in batch}

The Verhulst logistic kinetic model (Verhulst, 1838) was used to describe the experimental growth evolution in the reactor in batch mode, and the kinetic growth parameters were obtained. The Verhulst model (Eq. 1) has been utilized as a fundamental growth model in ecological studies because of its mathematical simplicity and simple biological definition. It is expressed mathematically as follows:

$\frac{\delta X}{\delta t}=\mu X\left[1-\frac{X}{X_{\mathrm{m}}}\right]$

\subsection{Volumetric productivity in continuous photobioreactors}

Kinetic growth parameters obtained in batch phase are useful not only for comparative purposes between different experimental 
conditions in batch; they can also be used to predict the growth in continuous operation.

In order to estimate the productivity of a continuous reactor with a growth kinetic equal to that observed in batch phase, a mass balance has to be performed.

The mass balance for the biomass in the reactor is:

$\frac{\delta m}{\delta t}=m_{\text {in }}-m_{\text {out }}+m_{\text {prod }}$

Considering the reactor in stationary conditions, and assuming that the feedstock does not contain microalgae,

$m_{\text {out }}=m_{\text {prod }}$

$Q X_{\text {out }}=V\left(\frac{\delta X}{\delta t}\right)_{\text {reactor }}$

Most continuous experiments at lab scale are performed in well-mixed reactors, where biomass concentration in effluent is equal to biomass concentration in reactor,

$Q X=V\left(\frac{\delta X}{\delta t}\right)_{\text {reactor }}$

Substituting Eq. 1 in Eq. 5:

$X=X_{\mathrm{m}}\left(1-\frac{1}{\mu \theta}\right)$

In a continuous reactor volumetric productivity can be calculated by means of:

$P=\frac{m_{\text {out }}}{V}=\frac{Q X}{V}=\frac{X}{\theta}$

Combining Eq. 6 and Eq. 7:

$P=X_{m}\left(\theta^{-1}-\frac{1}{\mu} \theta^{-2}\right)$

Eq. 8 relates continuous volumetric productivity with HRT and kinetic growth parameters obtained in a batch experiment. When representing this function, a maximum value for $P$ is observed (Fig. 2).

The HRT to obtain this maximum productivity will be:

$\frac{\delta P}{\delta \theta}=X_{\mathrm{m}}\left(-\theta^{-2}+\frac{2}{\mu} \theta^{-3}\right)=0$

Working out the value of the $H R T$ at maximum productivity $\left(\theta_{P}\right)$ :

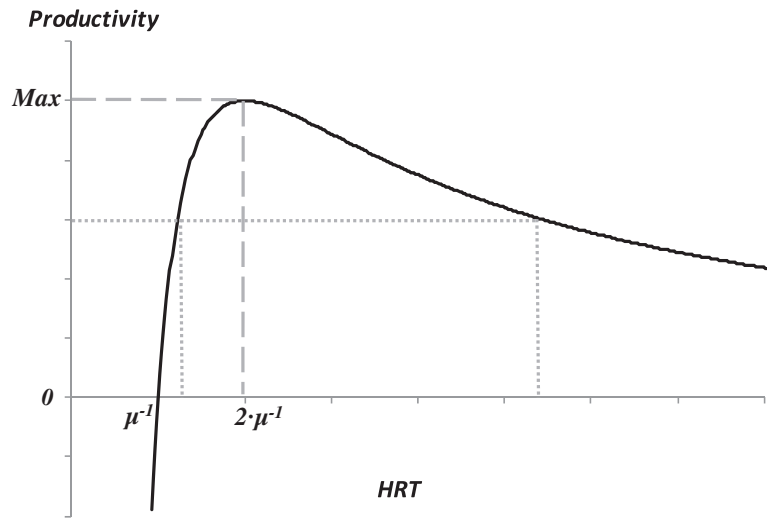

Fig. 2. Example of predicted productivity versus $H R T$. Maximum productivity is observed when the HRT is equal to 2 divided by the maximum specific growth rate (dashed lines). Dotted lines represent two alternative HRTs for the same productivity value.
$\theta_{P}=\frac{2}{\mu}$

\section{Results and discussion}

\subsection{Batch phase}

The photobioreactor was operated first in batch mode until the stationary phase was reached, then continuous supply of the medium was started and the reactor was operated in chemostat. The sample of secondary effluent used in this phase presented concentrations of total nitrogen and total phosphorus of 31.0 and $1.63 \mathrm{mg} \mathrm{l}^{-1}$ respectively. Nitrogen and phosphorus contents were typical of this kind of stream; the N:P molar ratio was 42 , which is much higher than 16 , the theoretical ratio required for the growth of phytoplankton (Redfield, 1958). This nutrient concentration was higher than the most restrictive discharge requirements regulated by the European Union for wastewaters (European Commission Directive, 1998); therefore this is wastewater that would need to be treated. In the batch phase, total phosphorus was completely removed in $2 \mathrm{~h}$ and complete total nitrogen uptake took place after $80 \mathrm{~h}$.

Temporal evolution shows a typical growth curve, exhibiting a barely perceptible lag phase followed by an exponential growth phase and a stationary phase. Experimental biomass growth in batch phase is depicted in Supplementary material 1 as dots. The lag phase was quite short or even non-existent, indicating wastewater conditions were not too different from those in the synthetic media used to grow the inoculum. The batch phase ended when the stationary phase was reached.

The integrated form of Eq. 1 subject to an initial value of $X=X o$ $(t=0)$ was used to describe the experimental data of growth:

$X=\frac{X_{o} X_{m} e^{\mu t}}{X_{m}-X_{o}+X_{o} e^{\mu t}}$

The non-linear regression of the batch experimental data results in the growth kinetic parameters is shown in Table 1 . The values predicted by the Verhulst model appear in Supplementary material 1 as solid lines. The experimental values obtained fit this logistic model and the proportion of variance explained by the equation was higher than $99 \%$.

Batch productivity has been calculated according to Eq. 12, proposed by Ruiz et al. (in press), which is considered a better approximation than the classic Eq. 13 calculation for productivity. Eq. 12 excludes the lag phase and the stationary phase of batch growth; the exponential growth phase is more relevant since, in continuous growth, the culture will be in this phase.

Productivity $=\frac{X_{90}-X_{10}}{t_{90}-t_{10}}=\frac{0.9 X_{m}-1.1 X_{0}}{t_{90}-t_{10}}$

Classic Productivity $=\frac{\Delta X}{\Delta t}=\frac{\left(X_{\mathrm{m}}-X_{o}\right)}{\left(t_{m}-t_{0}\right)}$

The specific growth rate observed in batch phase was $0.94 \mathrm{~d}^{-1}$ (Table 1), similar to the rates of 1.25 and $1.05 \mathrm{~d}^{-1}$ obtained by Hodaifa et al. (2012) and Martínez et al. (2000) respectively for

Table 1

Kinetic growth parameters of batch phase from the Verhulst model.

\begin{tabular}{|c|c|}
\hline Parameters & \\
\hline$X_{\mathrm{o}}\left(\mathrm{mg} \mathrm{SS} \mathrm{L}^{-1}\right)$ & $87 \pm 19$ \\
\hline$X_{\mathrm{m}}\left(\mathrm{mg} \mathrm{SS} \cdot \mathrm{L}^{-1}\right)$ & $1.439 \pm 39$ \\
\hline$\mu\left(\mathrm{d}^{-1}\right)$ & $0.94 \pm 0.08$ \\
\hline Batch productivity (g SS $\cdot 1^{-1} \mathrm{~d}^{-1}$ ) & 0.23 \\
\hline$R$ & 0.99 \\
\hline
\end{tabular}


batch cultures of $S$. obliquus in effluents from wastewater treatment plants. Higher and lower specific growth rates for Scenedesmus sp. in treated wastewater in batch operation have been obtained by McGinn et al. (in press) $\left(1.39 \mathrm{~d}^{-1}\right)$ and Xin et al. (2010) $\left(0.2 \mathrm{~d}^{-1}\right)$, probably due to differences in the experimental conditions used. McGinn et al. (in press) used continuous illumination, while Xin et al. (2010) used a much lower light intensity (55-60 $\mu \mathrm{mol} \mathrm{m}^{-2} \mathrm{~s}^{-1}$ ), and the culture was not aerated.

The productivity obtained in batch operation was $0.23 \mathrm{~g} \mathrm{SS} \cdot \mathrm{l}^{-1}$ $\mathrm{d}^{-1}$ (Table 1$)$, higher than the value $\left(0.13 \mathrm{~g} \mathrm{SS} \cdot \mathrm{l}^{-1} \mathrm{~d}^{-1}\right)$ obtained for Scenedesmus sp. in treated wastewater in batch operation by McGinn et al. (in press). However the method used by these authors to estimate the productivity was different: they multiplied the biomass concentration by the specific growth rate. Other authors have reported higher productivities $\left(0.38 \mathrm{~g} \mathrm{SS} \cdot \mathrm{l}^{-1} \mathrm{~d}^{-1}\right)$ for S. obliquus in synthetic medium (Ho et al., 2010).

\subsection{Continuous phase}

After the batch phase, the photobioreactor was operated in continuous mode in order to check whether the values predicted by Eqs. 6 and 8 fitted the experimental values.

An overview of all steady-state data is given in Table 2, where the nitrogen and phosphorus concentrations for each experiment are given for the influent and the effluent together with the biomass concentration and productivity.

The $\mathrm{pH}$ of the culture was $7.0 \pm 0.3$ during the experiment, due to continuous $\mathrm{CO}_{2}$ addition in the aeration. Changes in biomass concentration did not induce increases in $\mathrm{pH}$ : so although there was photosynthetic activity in the culture, the continuous injection of air enriched in $\mathrm{CO}_{2}$ had a strong effect on the $\mathrm{pH}$.

\subsubsection{Biomass growth}

In this study different steady states were achieved when culturing $S$. obliquus in chemostat. When comparing batch $X_{\mathrm{m}}$ (Table 1) and biomass concentrations in continuous operation (Table 2 and Fig. 3), it can be observed that the latter were lower regardless of the dilution rate. However, productivities were greater in chemostats, which is when medium was added continuously. The explanation for this finding must be that in chemostats, the biomass was continuously in exponential growth phase, despite attempting in this work to attenuate the effect of the lag and stationary phases when calculating batch productivity (Eq. 12). The results of this study agree with those obtained by McGinn et al. (in press) for Scenedesmus sp. in secondary effluent, where productivities in batch were almost half those obtained in chemostats. It is notable that the productivities in chemostats obtained by those authors were 0.23 and $0.27 \mathrm{~g}$ dry weight $\cdot \mathrm{l}^{-1} \mathrm{~d}^{-1}$, values similar to those obtained in the present study (Table 2 ).

When the HRT decreased, biomass concentration and productivity levels also varied (Table 2 and Fig. 3). With a HRT of $2.8 \mathrm{~d}$, productivity and biomass concentration values were higher than with $3.4 \mathrm{~d}$; both parameters reached their maximum value at a HRT of

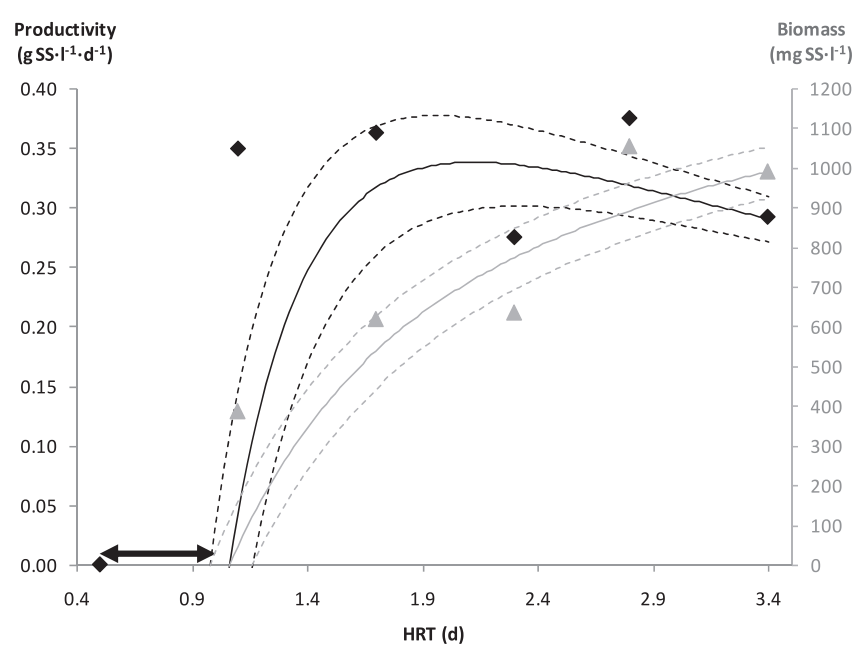

Fig. 3. Biomass productivity and dry weight concentrations plotted against HRT Symbols are experimental data and lines are predicted data according to batch phase (Eqs. (6) and (8)). Predicted data depicted as dashed line are maximum and minimum values according to standard error obtained when the batch growth kinetic model is applied. Arrows indicate the zone where experimental HRT could produce reactor wash-out.

$2.8 \mathrm{~d}$. The values of these parameters were progressively lower at HRTs of less than $2.8 \mathrm{~d}$. The decline in biomass concentration was especially pronounced when the HRT was changed from 2.8 to $2.3 \mathrm{~d}$, and from 1.7 to $1.1 \mathrm{~d}$. However, in this latter case, the decline in productivity was not very pronounced. Martínez Sancho et al. (1999) also found a decrease in biomass concentration when the HRT was increased, in continuous culture of S. obliquus.

From the kinetic results obtained in the batch phase (Table 1 ), theoretical biomass concentration (Eq. 6) and productivity (Eq. 8) in continuous operation can be estimated as a function of the dilution rate. In Fig. 3, experimental values (dots) and predicted values (lines) are represented for comparison. The result is considered quite satisfactory, particularly considering the changing composition of wastewater as culture medium. A better fit is expected to be obtained when using a synthetic culture medium, sterile and with a constant composition.

As shown in Fig. 3, predicted and experimental continuous productivities were quite similar at most of the HRTs tested. Experimental continuous productivities for HRTs of 3.4, 1.7 and $0.5 \mathrm{~d}$ were consistent with predicted productivities, i.e., between maximum and minimum predicted values according to the standard error of the batch growth kinetic model. Differences between experimental and predicted continuous productivities for HRTs of 2.8 and $2.3 \mathrm{~d}$ were less than $10 \%$; the greatest difference is found in the comparison of values corresponding to an HRT of $1.1 \mathrm{~d}$.

A theoretical maximum continuous productivity should have been obtained when the $H R T$ was around 2.12 d, i.e., $\theta_{P}=2 \mu^{-1}$ (Eq. 10). However, the maximum productivity in chemostat

Table 2

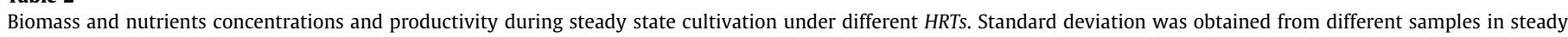
state.

\begin{tabular}{|c|c|c|c|c|c|c|}
\hline \multicolumn{7}{|l|}{$H R T(\mathrm{~d})$} \\
\hline & 0.5 & 1.1 & 1.7 & 2.3 & 2.8 & 3.4 \\
\hline$S S\left(\mathrm{mg} \mathrm{l}^{-1}\right)$ & $0 \pm 0$ & $388 \pm 13$ & $619 \pm 33$ & $635 \pm 66$ & $1,052 \pm 69$ & $989 \pm 40$ \\
\hline Productivity (g SS $\cdot \mathrm{l}^{-1} \mathrm{~d}^{-1}$ ) & $0 \pm 0$ & $0.35 \pm 0.01$ & $0.36 \pm 0.02$ & $0.28 \pm 0.03$ & $0.38 \pm 0.02$ & $0.29 \pm 0.01$ \\
\hline $\mathrm{TN}$ in $\left(\mathrm{mg} \mathrm{l}^{-1}\right)$ & 16.6 & 19.7 & 22.2 & 15.2 & 34.9 & 17.7 \\
\hline TN out $\left(\mathrm{mg} \cdot \mathrm{l}^{-1}\right)$ & $16.6 \pm 0$ & $2.0 \pm 0.5$ & $2.0 \pm 0.6$ & $1.7 \pm 0.02$ & $4.6 \pm 1.0$ & $3.4 \pm 2.7$ \\
\hline$T P$ in $\left(\mathrm{mg} \mathrm{l}^{-1}\right)$ & 2.0 & 1.75 & 2.14 & 0.81 & 3.56 & 1.57 \\
\hline TP out $\left(\mathrm{mg} \mathrm{l}^{-1}\right)$ & $2.0 \pm 0$ & $0.09 \pm 0.02$ & $0.07 \pm 0.01$ & $0.08 \pm 0.01$ & $0.08 \pm 0.01$ & $0.08 \pm 0.01$ \\
\hline
\end{tabular}


obtained in this study corresponded to an HRT of $2.8 \mathrm{~d}$. This result was not consistent with the predicted value, probably due to the phosphorus content in the wastewater of this steady state (Table 2 ) which was significantly higher (more than double) than that in the batch phase used to predict continuous productivity (Section 3.1.), which could support further growth.

As can be observed in Fig. 3, for HRT values lower than the inverse of the maximum specific growth rate $\left(\mu^{-1}\right)$, productivity takes a negative value. This indicates that microalgae are being washed out, since biomass HRT is shorter than the time needed for microalgae to double. In this work a HRT of $0.5 \mathrm{~d}$ was also tested, but steady state was not reached due to biomass washout. Therefore, there is a critical point for the HRT between 1.1 and $0.5 \mathrm{~d}$, which causes a wash-out of the reactor. This confirms the theory that HRTs of less than $\mu^{-1}$ are critical in producing reactor wash-out.

Considering biomass concentration, experimental values followed the same trend as predicted (Fig. 3). Therefore, based on kinetic growth parameters obtained from a batch experiment, using the Verhulst model, biomass concentrations and productivities in continuous operation could be estimated as a function of HRT of the culture .

According to Eq. 7, the same value for continuous productivity can be obtained with two different HRTs (depicted in Fig. 2). Therefore to reach a target value of productivity, two operating strategies could be applied: one with a long $H R T$, involving a high biomass concentration (Eq. 6) or another with a short HRT and a low biomass concentration.

Considering two scenarios with the same reactor volume and productivities, operating at two different HRTs, the reactor with the shorter HRT will treat a greater volume of wastewater per unit of time. However, as biomass concentration in the effluent would be lower (Eq. 6), harvesting costs per unit of biomass produced would be higher for a shorter HRT.

On the other hand, for a given flow of wastewater to treat, a higher capacity reactor would be needed for a longer $H R T$, entailing higher capital expenditure. However harvesting costs per unit of biomass produced remain lower, as biomass concentration would be higher and more microalgae would be obtained per unit volume of treated water.

Depending on the objectives (treating wastewater or producing biomass), an appropriate operating strategy should be selected. To treat wastewater, short HRTs are preferred, provided the time is long enough to remove nutrients. On this point, Martínez Sancho et al. (1999) established that dilution rates for maximum biomass productivity were lower than those for maximum phosphorus removal.

\subsubsection{Nutrient removal}

The filtered culture was analyzed for total nitrogen, total phosphorus and COD to determine the process performance of the different HRTs tested.

COD was below the discharge value set by European Commission Directive (1991) (125 mg O $\left.\mathrm{O}_{2} \cdot \mathrm{l}^{-1}\right)$ in influent wastewater. COD in the filtered effluent from the reactor remained almost unchanged, also meeting the discharge value. Some species of microalgae present the ability to grow mixotrophically, using organic compounds under illumination (Cheirsilp and Torpee, 2012). However, effluents from WWTPs usually present low COD and mainly as organic carbon that cannot be assimilated; this is the reason why the COD in the effluent from the flat panel reactor does not decrease.

Total nitrogen and total phosphorus concentrations in the wastewater and in the filtered effluent are shown in Table 2. Except for the HRT of $0.5 \mathrm{~d}$, where microalgae were washed out and nutrients were not removed, nitrogen and phosphorus concentrations in the effluent were below $10 \mathrm{mg} \mathrm{TN} \cdot \mathrm{l}^{-1}$ and $1 \mathrm{mg} \mathrm{TP} \cdot \mathrm{I}^{-1}$ respectively, regardless of the $H R T$. These are minimum discharge values set by European Commission Directive (1998) concerning urban wastewater treatment.

As stated in Section 3.2.1., short HRTs are preferred for treating wastewater, as the reactor required would be smaller. For this objective, the HRT should be as short as possible, provided nutrient removal meets the regulations for wastewater discharge. In this study, the reactor could be operated at a $H R T$ of $1.1 \mathrm{~d}$, with nitrogen and phosphorus concentrations being below regulation limits, and avoiding reactor wash-out. This result agrees with that reported by Martínez Sancho et al. (1999), who studied the removal of phosphorus by $S$. obliquus in chemostat, and established an efficient phosphorus removal rate at a $H R T$ value close to the dilution rate that washes out the biomass.

Phosphorus concentrations in the effluent were close to the detection limit of the technique, indicating complete removal $\left(0.04 \mathrm{mg} \mathrm{TP} \cdot \mathrm{l}^{-1}\right)$, whereas nitrogen was not completely depleted from the medium (Table 2). This excess of nitrogen in the medium suggested that phosphorus could be the limiting nutrient in this culture medium. In addition, the $\mathrm{N}: \mathrm{P}$ (molar) ratio in the influent presented an average of 25 , which is higher than 16 , the theoretical value required for the growth of phytoplankton (Redfield, 1958); this can be used as a general formula to estimate the nutrient limitation in the culture medium.

In Fig. 4, the evolution of nitrogen and phosphorus removal can be observed as a function of the HRT. A trend was observed; without considering the critical HRT which washes out the biomass (HRT $0.5 \mathrm{~d}$ ), the shorter the HRT the larger the amount of nutrients removed from the wastewater (Fig. 4). As previously mentioned, this confirms the conclusion that operating with a short HRT is the best strategy for treating wastewater (a high nutrient removal rate combined with low biomass production rates).

When biomass was washed out (at a HRT of $0.5 \mathrm{~d}$ ) the nutrient removal rate was zero, as the wastewater output of the reactor remained untreated (Fig. 4). For all other values of $H R T$, removal rates of nitrogen and phosphorus were between 13.5 and $4.2 \mathrm{mg} \mathrm{TN} \cdot \mathrm{l}^{-1}$ $\mathrm{d}^{-1}$ and 1.49 and $0.32 \mathrm{mg} \mathrm{TP} \cdot \mathrm{l}^{-1} \mathrm{~d}^{-1}$, respectively. This is consistent with the nitrogen removal rates reported by Voltolina et al. (2005) in semicontinuous cultures of $S$. obliquus in artificial wastewater, where nitrogen removal rates of 9.27 and $8.45 \mathrm{mg} \mathrm{N} \cdot \mathrm{l}^{-1} \mathrm{~d}^{-1}$ for $30 \%$ and $40 \%$ dilutions, respectively, were reported. For Scenedesmus sp. in secondary effluent under continuous illumination McGinn et al. (in press) reported slightly higher assimilation rates $\left(24.4 \mathrm{mg} \mathrm{N} \cdot \mathrm{l}^{-1} \mathrm{~d}^{-1}\right.$ and $2.8 \mathrm{mg} \mathrm{P} \cdot \mathrm{l}^{-1} \mathrm{~d}^{-1}$ ), probably due to

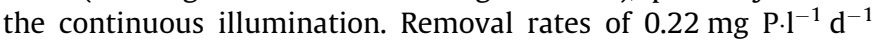
have been reported by Martínez Sancho et al. (1999).

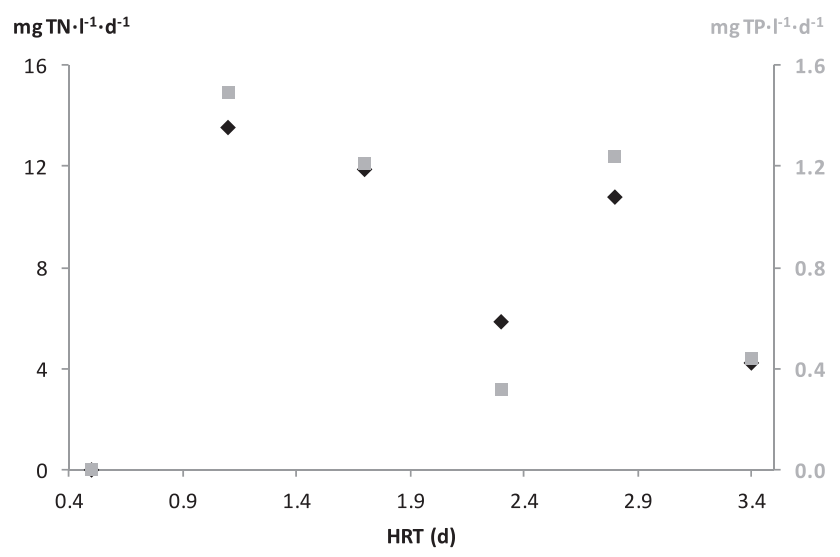

Fig. 4. Evolution of the amount of nutrients removed per liter of reactor and unit time in stationary state as a function of the HRT 

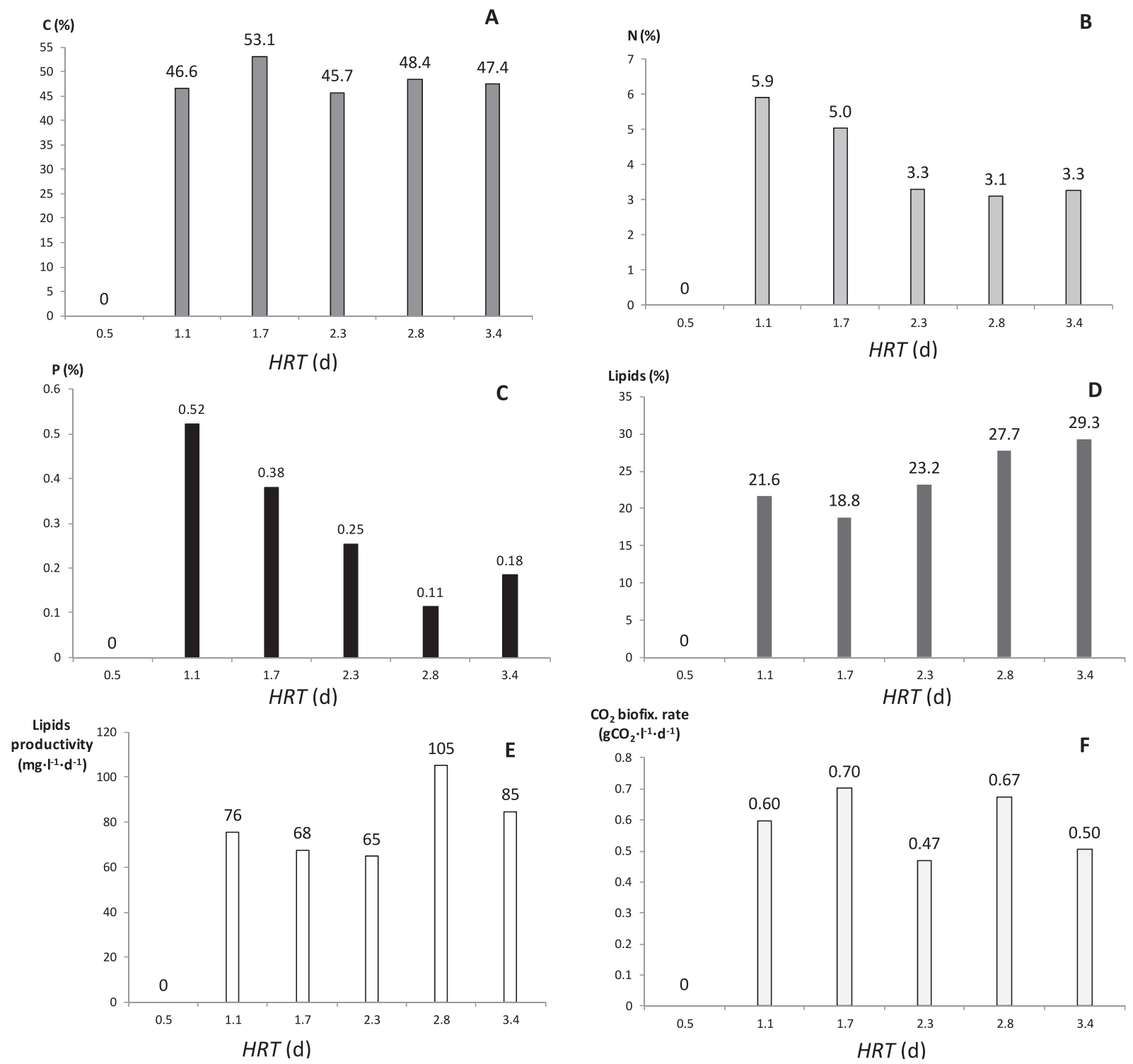

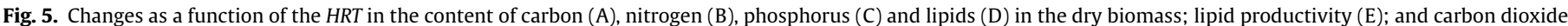
biofixation rate $(F)$.

\subsubsection{Biomass composition}

Analysis of the biomass is shown in Fig. 5. At an HRT of $0.5 \mathrm{~d}$, the reactor was washed out and consequently biomass no biomass was obtained; therefore no value is shown for compositional analysis at the lowest HRT tested.

Biomass content in carbon was relatively constant (48 $\pm 3 \%$ ) regardless of the $H R T$ (Fig. 5A). However, internal nitrogen and phosphorus content do depend on the HRT; at longer HRTs, the biomass content in these nutrients is decreased (Fig. 5B and C). This indicates that, to obtain a biomass with high nitrogen and phosphorus content, a short HRT is desirable. Boelee et al. (2011) reported similar trends in carbon, phosphorus and nitrogen content for microalgae cultured in municipal effluent.

Nitrogen content of the biomass was between $5.9 \%$ and $3.1 \%$ (Fig. 5B). In studies where Scenedesmus sp. has been grown in secondary effluent, similar nutrient composition has been obtained, e.g., 3.3\% nitrogen (Hodaifa et al., 2012). Carbon content in biomass obtained (Fig. 5A) agrees with the result of $45 \% \mathrm{C}$ reported by Boelee et al. (2011).

According to Brennan and Owende (2010), a high content of proteins in biomass is associated with low C:N ratios. In this study, when the HRT was shorter, the biomass $\mathrm{C}: \mathrm{N}$ ratio was decreased (data obtained from Fig. 5A and B); this suggests an increase in biomass protein content. When more nitrogen is available the metabolism changes to protein production, because nitrogen is an essential constituent of proteins in algal cells (Richmond, 2004).

Regarding the lipids content measured in the dry biomass, this was in the range between $18.8 \%$ and $29.3 \%$ (Fig. 5D). These percentages are consistent with those reviewed from literature data by Griffiths and Harrison (2009) for S. obliquus; these authors reported lipid content of between $21 \%$ for a nutrient-replete medium and $42 \%$ for a nutrient-deficient medium.

As can be observed in Fig. 5D, there is a downward trend in lipid content at shorter HRTs. Therefore, the lower the nitrogen content, the higher the lipid percentage. This finding is consistent with numerous studies which show that biosynthesis and accumulation of lipids is enhanced in nitrogen-limited or -deprived cultures of microalgae (Richmond, 2004).

Lipid productivity (Fig. 5E) is obtained as the product of lipid content of the biomass (Fig. 5D) and continuous productivity of biomass (Table 2). Maximum lipid productivity is achieved from a balance between lipid content and biomass productivity. This 
maximum value was obtained at a $H R T$ of $2.8 \mathrm{~d}$ (105 mg lipids. $\mathrm{l}^{-1}$ $\left.\mathrm{d}^{-1}\right)$, where biomass productivity was the highest value obtained $\left(0.38 \mathrm{~g} \mathrm{SS} \cdot \mathrm{l}^{-1} \mathrm{~d}^{-1}\right)$ and lipid content was one of the highest values obtained (27.7\%).

\subsubsection{Carbon dioxide biofixation rate}

The carbon dioxide biofixation rate was calculated from the carbon content value of the biomass using Eq. 12:

$$
P_{\mathrm{CO}_{2}}=\% \mathrm{C} \cdot \text { Productivity } \cdot\left(\frac{M M_{\mathrm{CO}_{2}}}{M M_{\mathrm{C}}}\right)
$$

Values obtained ranged between 0.47 and $0.70 \mathrm{~g} \mathrm{CO}_{2} \cdot \mathrm{l}^{-1} \mathrm{~d}^{-1}$ (Fig. 5F), productivity being the most influential factor, since carbon content was quite homogeneous among samples.

\subsubsection{Potential biomethane valorization}

Anaerobic digestion appears to be the most straightforward process for obtaining energy from microalgae, since it does not require intensive biomass concentration, drying or oil extraction; it is thus a promising energy conversion process (Alzate et al., 2012; Lakaniemi et al. (in press)). An important factor in anaerobic digestion is the biochemical composition of the biomass. Of the constituents of biomass - proteins, carbohydrates and lipids - these last present the highest specific methane yield (Sialve et al., 2009); on the other hand, a high percentage of proteins could hamper the digestion due to the toxic effect of the ammonia released (Ras et al., 2011).

Hence, the optimum HRT for obtaining the most suitable biomass for anaerobic digestion will be that which produces a biomass rich in lipids and with low protein content. The longer the $H R T$ the greater the possibilities of producing a biomass meeting these two criteria (Fig. 5B-D). Maximum biogas production is also directly related to maximum biomass production. As previously commented, for the same biomass productivity, two alternative operating strategies can be considered (Fig. 2). For biogas production the low HRT option is less suitable, as biomass composition implies high protein and low lipids content. Therefore operating at a longer $H R T$ produces a biomass that is more suitable for anaerobic digestion.

\section{Conclusions}

Based on batch kinetic growth parameters, biomass concentrations and productivities under continuous conditions can be satisfactorily predicted as a function of the dilution rate.

To obtain maximum biomass productivity and maximum $\mathrm{CO}_{2}$ biofixation, the HRT should be 2 divided by the maximum specific growth rate obtained under similar batch conditions. However, for biodiesel or biogas production, the HRT should be higher than the optimum for biomass production. If the objective is the maximum removal of nutrients, the HRT should, under discharge requirements, be as close as possible to the inverse of the maximum specific growth rate in batch mode.

\section{Acknowledgements}

The authors would like to thank the Regional Government of Andalusia (Consejería de Innovación, Ciencia y Empresa, Junta de Andalucía, Spain) for funding this study [Ref: P08-TEP-03854]. This is the CEIMAR journal publication 16 .

\section{References}

Alzate, M.E., Muñoz, R., Rogalla, F., Fdz-Polanco, F., Pérez-Elvira, S.I., 2012. Biochemical methane potential of microalgae: influence of substrate to inoculum ratio, biomass concentration and pretreatment. Bioresour. Technol. $123,488-494$.
American Public Health Association, A.W.W.A., Water Environment Federation, 1992. Standard Methods for the Examination of Water and Wastewater, 18th ed. APHA-AWWA-WEF, Washington DC, USA.

Boelee, N.C., Temmink, H., Janssen, M., Buisman, C.J.N., Wijffels, R.H., 2011. Nitrogen and phosphorus removal from municipal wastewater effluent using microalgal biofilms. Water Res. 45 (18), 5925-5933.

Brennan, L., Owende, P., 2010. Biofuels from microalgae-a review of technologies for production, processing, and extractions of biofuels and co-products. Renew. Sust. Energ. Rev. 14 (2), 557-577.

Cheirsilp, B., Torpee, S., 2012. Enhanced growth and lipid production of microalgae under mixotrophic culture condition: effect of light intensity, glucose concentration and fed-batch cultivation. Bioresour. Technol. 110, 510-516.

European Commision Directive C. 21 May, 1991. Concerning Urban Waste-Water Treatment, vol. 91/271/EC. Off. J. Eur. Comm., 40-52.

European Commission Directive C. 27 Feb, 1998. Amending Council Directive 91/ 271/EEC with respect to certain requirements established in Annex I, vol. 98/15/ EC. Off. J. Eur. Comm., 29-30.

Gouveia, L., Oliveira, A.C., 2009. Microalgae as a raw material for biofuels production. J. Ind. Microbiol. Biot. 36 (2), 269-274.

Griffiths, M., Harrison, S., 2009. Lipid productivity as a key characteristic for choosing algal species for biodiesel production. J. Appl. Phycol. 21 (5), 493-507.

Henze, M., Grady, C.P.L.Jr., Gujer, W., Marais, G.v.R., Matsuo, T., 1987. Activated Sludge Model No. 1. IAWPRC Scientific and Technical Report No. 1, IWA, London, UK.

Ho, S.H., Chen, C.Y., Yeh, K.L., Chen, W.M., Lin, C.Y., Chang, J.S., 2010. Characterization of photosynthetic carbon dioxide fixation ability of indigenous Scenedesmus obliquus isolates. Biochem. Eng. J. 53 (1), 57-62.

Hodaifa, G., Martínez, M.E., Órpez, R., Sánchez, S., 2012. Inhibitory effects of industrial olive-oil mill wastewater on biomass production of Scenedesmus obliquus. Ecol. Eng. 42, 30-34.

Kennish, M.J., de Jonge, V.N., 2012. Chemical Introductions to the Systems Diffuse and Nonpoint Source Pollution from Chemicals Nutrients Eutrophication. In: McLusky, D., Wolanski, E. (Eds.), Treatise on Estuarine and Coastal Science Human-induced Problems (Uses and Abuses). Elsevier, Oxford UK, p. 315, Vol. 8

Kilham, S., Kreeger, D., Lynn, S., Goulden, C., Herrera, L., 1998. COMBO: a defined freshwater culture medium for algae and zooplankton. Hydrobiologia 377 (1), 147-159.

Köthe, J., Bitsch, R., 1992. Oxisolv ${ }^{\circledR}$ plus microwave - a new way for sample pretreatment and sample preparation. Fresen. J. Anal. Chem. 343 (9-10), 717718 .

Lakaniemi, A.-M., Tuovinen, O.H., Puhakka, J.A., 2012. Anaerobic conversion of microalgal biomass to sustainable energy carriers - a review. Bioresour. Technol.

Martínez, M.E., Sánchez, S., Jiménez, J.M., El Yousfi, F., Muñoz, L., 2000. Nitrogen and phosphorus removal from urban wastewater by the microalga Scenedesmus obliquus. Bioresour. Technol. 73 (3), 263-272.

Martínez Sancho, M., Jiménez Castillo, J.M., El Yousfi, F., 1999. Photoautotrophic consumption of phosphorus by Scenedesmus obliquus in a continuous culture Influence of light intensity. Process Biochem. 34 (8), 811-818.

McGinn, P.J., Dickinson, K.E., Park, K.C., Whitney, C.G., MacQuarrie, S.P., Black, F.J., Frigon, J.C., Guiot, S.R., O'Leary, S.J.B., 2012. Assessment of the bioenergy and bioremediation potentials of the microalga Scenedesmus sp. AMDD cultivated in municipal wastewater effluent in batch and continuous mode. Algal Res.

Ras, M., Lardon, L., Bruno, S., Bernet, N., Steyer, J.-P., 2011. Experimental study on a coupled process of production and anaerobic digestion of Chlorella vulgaris. Bioresour. Technol. 102 (1), 200-206.

Redfield, A.C., 1958. The biological control of chemical factors in the environment. Am. Sci. 46, 205-211.

Richmond, A., 2004. Handbook of Microalgal Culture: Biotechnology and Applied Phycology. Wiley-Blackwell, Oxford.

Ruiz, J., Álvarez, P., Arbib, Z., Garrido, C., Barragán, J., Perales, J.A., 2011. Effect of nitrogen and phosphorus concentration on their removal kinetic in treated urban wastewater by Chlorella vulgaris. Int. J. Phytoremediation 13 (9), 884-896.

Ruiz, J., Arbib, Z., Âlvarez-Díaz, P.D., Garrido-Pérez, C., Barragán, J., Perales, J.A., 2012. Photobiotreatment model (PhBT): a kinetic model for microalgae biomass growth and nutrient removal in wastewater. Environ. Technol. DOI: http:// dx.doi.org/10.1080/09593330.2012.724451.

Sialve, B., Bernet, N., Bernard, O., 2009. Anaerobic digestion of microalgae as a necessary step to make microalgal biodiesel sustainable. Biotechnol. Adv. 27, 409-416.

Takagi, M., Karseno, Yoshida, T., 2006. Effect of salt concentration on intracellular accumulation of lipids and triacylglyceride in marine microalgae Dunaliella cells. J. Biosci. Bioeng. 101 (3), 223-226.

Verhulst, P.F., 1838. Notice sur la loi que la population suit dans son accroissement. Correspondance Mathematique et Physique 10,113-121.

Voltolina, D., Gómez-Villa, H., Correa, G., 2005. Nitrogen removal and recycling by Scenedesmus obliquus in semicontinuous cultures using artificial wastewater and a simulated light and temperature cycle. Bioresour. Technol. 96 (3), 359-362.

Wiltshire, K.H., Boersma, M., Möller, A., Buhtz, H., 2000. Extraction of pigments and fatty acids from the green alga Scenedesmus obliquus (Chlorophyceae). Aquat. Ecol. 34 (2), 119-126.

Xin, L., Hong-ying, H., Jia, Y., 2010. Lipid accumulation and nutrient removal properties of a newly isolated freshwater microalga, Scenedesmus sp. LX1, growing in secondary effluent. New Biotech. 27 (1), 59-63.

Zhang, E., Wang, B., Wang, Q., Zhang, S., Zhao, B., 2008. Ammonia-nitrogen and orthophosphate removal by immobilized Scenedesmus sp. isolated from municipal wastewater for potential use in tertiary treatment. Bioresour. Technol. 99 (9), 3787-3793. 